\title{
Beveling of Quartz Crystal Blanks: an Experimental Study
}

\author{
Chensong Dong ${ }^{*}$ \\ Department of Mechanical Engineering, Curtin University \\ GPO Box U1987, Perth, WA 6845, Australia
}

\begin{abstract}
An experimental study on the beveling of quartz crystal blanks is presented in this paper. Two issues in the beveling are addressed: beveling time and the shape of bevel. The time needed for beveling is determined by material removal rate. The concept of critical gap height is introduced to evaluate the bevel profile. In addition, a side effect, frequency shift is also studied. Seven potential relevant process factors: blank quantity, powder/blank ratio, powder type, machine rpm, powder changing time, barrel diameter and powder heating were identified. The influences of these process factors on material removal rate, critical gap height and frequency shift were studied using Design of Experiments (DOE). It is shown from the results that 1) machine rpm has the most significant effect on material removal rate, followed by barrel diameter. Material removal rate increases with machine rpm and barrel diameter; 2) steeper bevel profiles can be achieved by using barrels of smaller diameter and finer powders; and 3) machine rpm has the most significant effect on the frequency shift, followed by barrel diameter and powder type. The frequency shift increases with the machine rpm and barrel diameter. Using finer powders can reduce the frequency shift.
\end{abstract} Key words: Quartz crystal; bevel; Design of Experiments (DOE)

\footnotetext{
* Corresponding author. Tel: +61 (8) 92669204; fax: +61 (8) 92662681; email: c.dong@ curtin.edu.au.
} 


\section{Introduction}

A quartz crystal unit is a quartz wafer (also referred to as blank or crystal plate) to which electrodes have been applied, and which is hermetically sealed in a holder structure. AT-cut rectangular quartz crystal resonators are widely used for the high-precision applications such as mobile communication and GPS (global positioning system) equipment, because of their high temperature-frequency stability, and compatibility for mass production and miniaturization (Koyama et al. 1996; Sekimoto et al. 1997).

The most commonly used cut, AT-cut, was developed in 1934. In AT-cut, the plate contains the crystal's $x$ axis is inclined by $35^{\circ} 15^{\prime}$ from the $z$ (optic) axis. The frequency-temperature curve is a sine-shaped curve with the inflection point at around $25-35^{\circ} \mathrm{C}$. The frequency constant of AT-cut is $1.661 \mathrm{MHz} \cdot \mathrm{mm}$, i.e. the product of blank thickness (mm) and frequency $(\mathrm{MHz})$ is 1.661.

In order to achieve highly stable and reliable quartz crystal resonators without spurious response, quartz crystal blanks are finished into spherically contoured shape. The process of generating a spherical surface on a quartz plate is called beveling or contouring (Virgil 1982). Beveling is a modification to one or both of the major faces of a resonator plate in which the face is altered to have a partially spherical configuration; while contouring is a modification to one or both of the major faces of a resonator plate in which the face is altered to have a completely spherical configuration. It is called contouring if there is no flatness in the center, and beveling if there is flatness in the center. A beveled rectangular (also referred as strip) quartz crystal blank is shown in Figure 1.

Beveling or contouring has a drastic effect on the decoupling of modes by restricting the vibrating area of the plate to its central region by energy trapping effect. The frequency separation between the main and overtone modes is inversely proportional to the area of the vibrating region. Therefore, reducing the size of the vibrating area should cause the 
troublesome inharmonic modes to move to higher frequencies. Additionally, beveling or contouring offers the advantages of ease of mounting and reduced coupling to unwanted modes at the edge of the blank by restricting the blank's vibrating area to its central region (Salt 1987).

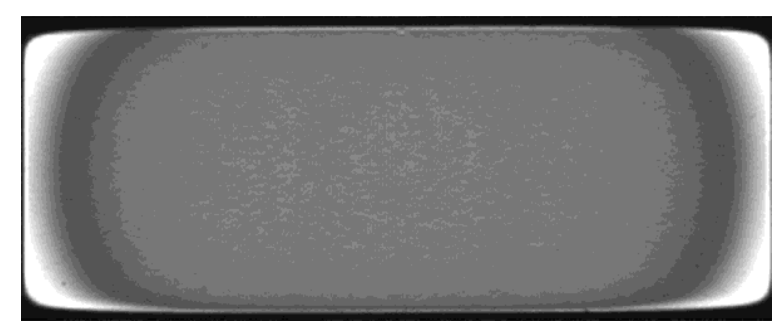

Figure 1: A beveled rectangular quartz crystal blank (white areas are thinner)

Two issues in the beveling of quartz crystal blanks are beveling time and the shape of bevel. The material removal of lapping and polishing processes has been extensively studied (Evans et al. 2003). In a lapping process, abrasive powders are mixed with a fluid carrier to form a slurry. The basic model of lapping and polishing was investigated by Preston (Preston 1927) in 1927. He proposed the polishing rate of material to be proportional to load and relative velocity. A critical size ratio for the characteristic particle size to film thickness was found by Williams and Hyncica (Williams and Hyncica 1992).

In a beveling process, no fluid is used. Similar to a lapping process, material is removed from crystal blanks by abrasive powders due to the relative movement between the blanks and beveling barrel. The difference from a lapping or polishing process is that the internal surface of a beveling barrel is spherical so that the gap between crystal blanks and the barrel's internal surface is non-uniform and this non-uniform gap determines the shape of bevel.

There is no open literature on the control of bevel profiles. In the semiconductor industry, wafers are beveled by mechanical grinding due to the large size of wafers. Chen et al. 
investigated the effect of wafer edge profile on wafer fracture reduction (Chen et al. 2010b) and ultimate mechanical strength (Chen et al. 2010a). The current beveling process development is mostly based on a trial-and-error approach because of the insufficient knowledge on the influences of process parameters. This limits the development of new generation crystal resonators. Thus, it is desirable to be able to know the best process parameter settings based on the beveled blank design information. In this paper, an experiment study on the beveling process of quartz crystal blanks is presented. The significant factors affecting material removal rate, critical gap height and frequency shift and their functional relationships have been discovered from the experimental results, which are useful for beveling process design and optimization.

\section{Beveling Process}

\section{Centrifugal beveling machine}

The beveling machine used in this study was EC-6A made by Engineering Sangyo, Japan, which was a centrifugal beveling machine consisting of a drum and four cylinders. Each cylinder can receive a number of beveling barrels. The internal profile of a beveling barrel consists of a series of inter-connected internal spheres. The diameter ranges from 60 to 200 $\mathrm{mm}$.

The beveling of quartz crystal blanks is schematically shown in Figure 2. Prior to beveling, a number of crystal blanks are prepared and weighed. The prepared blanks are mixed with abrasive powders at a certain weight ratio, and charged into beveling barrels. The charged beveling barrels are loaded into the four cylinders of the beveling machine. During the beveling process, the main drum rotates at a speed between 0 and $150 \mathrm{rpm}$, and the direction of rotation reverses intermittently. Because of the drum's rotation, the cylinders also selfrotate about their own axes. As a result of the drum's rotation, the crystal blanks are pressed 
against the beveling barrel's internal surface by the centrifugal force. The cylinders' selfrotation causes the relative movement between the crystal blanks and the beveling barrel's internal surface. Because of the friction, material is removed from the crystal blanks and bevel profiles are formed.

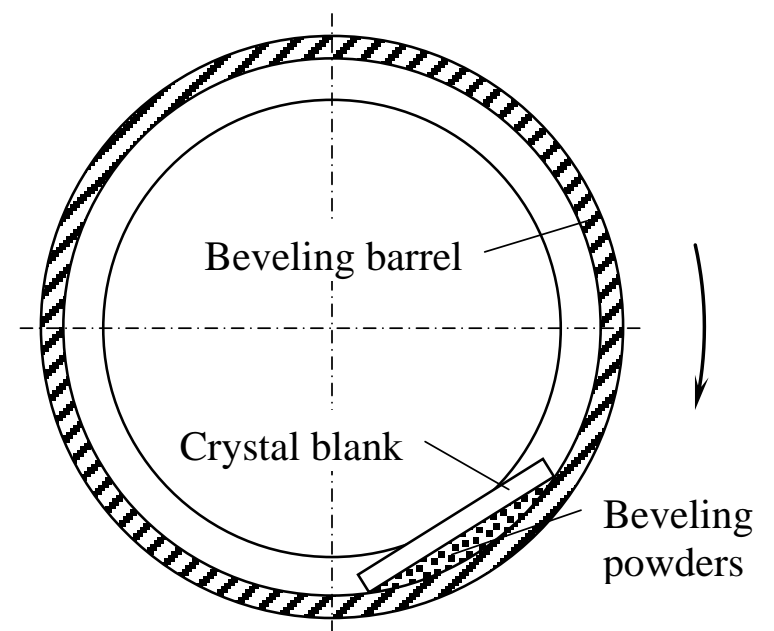

Figure 2: Beveling of quartz crystal blanks

\section{Abrasive powders}

The abrasive powders used in this beveling process are commercially available GC (Green Carborundum) powders. Grit sizes from GC800 to GC3000 were used in our production. The relationship between grit size and corresponding average particle diameter is given in Table 1.

Table 1: Powder type and its average particle size

\begin{tabular}{cc}
\hline Powder type & Average particle diameter $(\boldsymbol{\mu m})$ \\
\hline GC800 & 14 \\
GC1200 & 9.5 \\
GC1500 & 8 \\
GC2000 & 6.7 \\
GC3000 & 4 \\
\hline
\end{tabular}


The microscopic photos of GC800 powders in new and used conditions are shown in Figure 3. It is seen that new powder particles have very sharp corners. After 12-hour beveling, most sharp corners are rounded and large particles have broken into smaller ones. This indicates that beveling powders need to be changed periodically to maintain sufficient material removal rate.

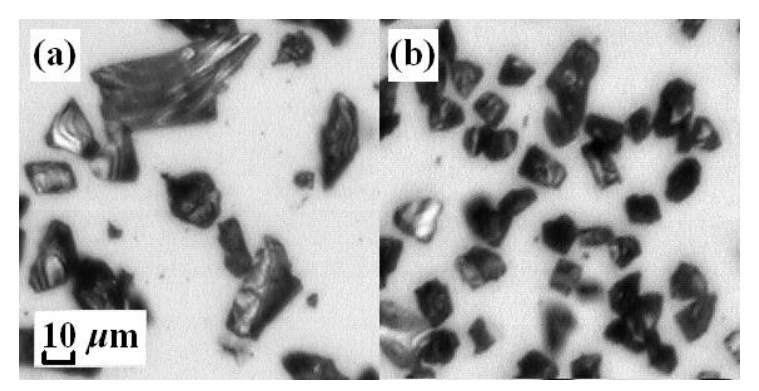

Figure 3: GC800 powders at magnification $\times 971$

\section{Material removal}

During beveling, a thin layer of abrasion powders is formed on the beveling barrel' internal surface. The nature of this problem is three-body abrasion, like that of the general lapping process. The ductile or brittle machining regime is an important mechanism in lapping brittle materials. Ductile regime has been referred to the machining state where the material is removed due to plastic deformation, as commonly observed for metallic materials, and brittle regime machining is referred to material removal associated with crack generation. Since quartz is a hard material, the beveling process is dominated by the brittle machining regime. For material removal under brittle regime machining, crack area is the key element in calculating the material removal rate, and it is dependent on pressure, particle sizes and barrel-blank gaps. 


\section{Critical gap height}

The gap between the beveling barrel and a crystal blank reaches its maximum at the center of the blank, i.e. the facet. This gap decreases and approaches zero towards the corner of the blank. When the barrel-blank gap decreases, beveling powders have a higher probability to create cracks on the blank surface, and the crack depth increases. Since material removal is due to cracks, material removal rate increases with decreasing barrel-blank gap, and the maximum material removal occurs near the blank edge, i.e.

$$
\begin{array}{ll}
m r r \propto \frac{1}{h} & h<h_{\text {crit }} \\
m r r=0 & h \geq h_{\text {crit }}
\end{array}
$$

It should be noted that in the real situation, material removal also occurs in the facet area. However, this material removal is neglected because (1) it is much less than that near the blank edge, and (2) it does not affect bevel profiles.

\section{Frequency shift}

Another important characteristic or side effect of the strip blank beveling process is frequency shift, i.e. the increase of frequency due to beveling. Frequency shift is mainly caused by the material being removed from the facet of crystal blanks. This unwanted frequency shift has to be offset in the design of crystal resonators. Thus, frequency shift prediction is very important. Since frequency shift increases with beveling time, frequency shift per hour was chosen to be investigated in this study. 


\section{Experimental Study}

\section{Design of experiments}

The main purpose of this experiment is to understand the influence of the process factors on bevel profiles, material removal rate and frequency shift. An AT-cut $16 \mathrm{MHz} 4.408 \times 1.768$

$\mathrm{mm}^{2}$ crystal blank was chosen to be investigated. Seven process factors were identified, and for each factor, two levels were chosen, as shown in Table 2.

Table 2: Factors and levels

\begin{tabular}{lcc}
\hline Factor & Low level & High level \\
\hline A: Blank quantity & 1000 & 4000 \\
B: Powder/blank ratio & 0.8 & 1.4 \\
C: Powder type & GC800 & GC1500 \\
D: Machine rpm & 75 & 140 \\
E: Powder changing time & 9 & 15 \\
F: Barrel diameter & 60 & 130 \\
G: Powder heating & No & Yes \\
\hline
\end{tabular}

The responses are material removal rate, critical gap height and frequency shift per hour. A $2^{7-4}$ factorial design was originally planned to reduce the number of experiment runs, since each experiment would run from 50 to 150 hours. In order to break the affiliation between main effects and two-factor interactions, this factorial design was augmented by fold-over on all factors. The design matrices of the original design and the fold over are shown in Table 3 and Table 4, respectively.

In each experiment run, crystal blanks were mixed with abrasive powders at the designed ratio and the mixture was charged into a beveling barrel. When the beveling was completed, 20 sample blanks were measured and the average bevel profile was obtained. In addition, the frequencies before and after beveling were measured and the frequency shift was calculated. 
Table 3: $2^{7-4}$ factorial design

\begin{tabular}{cccccccc}
\hline \multirow{2}{*}{$\begin{array}{c}\text { Std } \\
\text { order }\end{array}$} & $\begin{array}{c}\text { Blank } \\
\text { quantity }\end{array}$ & $\begin{array}{c}\text { Powder/blank } \\
\text { ratio }\end{array}$ & $\begin{array}{c}\text { Powder } \\
\text { type }\end{array}$ & $\begin{array}{c}\text { Machine } \\
\text { rpm }\end{array}$ & $\begin{array}{c}\text { Powder } \\
\text { changing } \\
\text { time }\end{array}$ & $\begin{array}{c}\text { Barrel } \\
\text { diameter }\end{array}$ & $\begin{array}{c}\text { Powder } \\
\text { heating }\end{array}$ \\
\cline { 2 - 7 } & $\mathbf{A}$ & $\mathbf{B}$ & $\mathbf{C}$ & $\begin{array}{c}\mathbf{D} \\
\mathbf{( - A B})\end{array}$ & $\begin{array}{c}\mathbf{E} \\
(-\mathbf{A C})\end{array}$ & $\begin{array}{c}\text { F } \\
\text { (-BC) }\end{array}$ & $\begin{array}{c}\text { G } \\
\text { (ABC) }\end{array}$ \\
\hline 1 & 1000 & 0.8 & 800 & 75 & 9 & 60 & 0 \\
2 & 4000 & 0.8 & 800 & 140 & 15 & 60 & 1 \\
3 & 1000 & 1.4 & 800 & 140 & 9 & 130 & 1 \\
4 & 4000 & 1.4 & 800 & 75 & 15 & 130 & 0 \\
5 & 1000 & 0.8 & 1500 & 75 & 15 & 130 & 1 \\
6 & 4000 & 0.8 & 1500 & 140 & 9 & 130 & 0 \\
7 & 1000 & 1.4 & 1500 & 140 & 15 & 60 & 0 \\
8 & 4000 & 1.4 & 1500 & 75 & 9 & 60 & 1 \\
\hline
\end{tabular}

Table 4: Fold over design

\begin{tabular}{cccccccc}
\hline \multirow{2}{*}{$\begin{array}{c}\text { Std } \\
\text { order }\end{array}$} & $\begin{array}{c}\text { Blank } \\
\text { quantity }\end{array}$ & $\begin{array}{c}\text { Powder/blank } \\
\text { ratio }\end{array}$ & $\begin{array}{c}\text { Powder } \\
\text { type }\end{array}$ & $\begin{array}{c}\text { Machine } \\
\text { rpm }\end{array}$ & $\begin{array}{c}\text { Powder } \\
\text { changing } \\
\text { time }\end{array}$ & $\begin{array}{c}\text { Barrel } \\
\text { diameter }\end{array}$ & $\begin{array}{c}\text { Powder } \\
\text { heating }\end{array}$ \\
\cline { 2 - 7 } & $\mathbf{- A}$ & $\mathbf{- B}$ & $\mathbf{- C}$ & $\begin{array}{c}\mathbf{D} \\
\text { (AB) }\end{array}$ & $\begin{array}{c}\mathbf{E} \\
(\mathbf{A C})\end{array}$ & $\begin{array}{c}\text { F } \\
(\mathbf{B C})\end{array}$ & $\begin{array}{c}\mathbf{G} \\
\text { (-ABC) }\end{array}$ \\
\hline 9 & 4000 & 1.4 & 1500 & 140 & 15 & 130 & 1 \\
10 & 1000 & 1.4 & 1500 & 75 & 9 & 130 & 0 \\
11 & 4000 & 0.8 & 1500 & 75 & 15 & 60 & 0 \\
12 & 1000 & 0.8 & 1500 & 140 & 9 & 60 & 1 \\
13 & 4000 & 1.4 & 800 & 140 & 9 & 60 & 0 \\
14 & 1000 & 1.4 & 800 & 75 & 15 & 60 & 1 \\
15 & 4000 & 0.8 & 800 & 75 & 9 & 130 & 1 \\
16 & 1000 & 0.8 & 800 & 140 & 15 & 130 & 0 \\
\hline
\end{tabular}

\section{Bevel profile measurement}

As a common practice of the crystal resonator industry, the bevel profile of a crystal blank is quantitatively characterized by two design parameters, viz. bevel width and bevel depth. As shown in Figure 4, the bevel width and bevel depth are the distances from the blank edge to the boundary of the facet in the length and width directions, respectively. Generally, these two design parameters can sufficiently define the bevel profile, and they are usually determined from blank profile measurement.

In order to quantitatively study the beveling process, bevel profiles need to be measured.

Since crystal blanks are usually very small and thin, contact measurement is unfeasible. Thus, in this study, a non-contact laser range sensor was used for bevel profile measurement. As 
shown in Figure 5, the bevel contour is a series of concentric circles. For simplicity, the bevel profile of a crystal blank was obtained by scanning along its centerline with the laser probe on a SmartScope ZIP 250 video and multisensor system and (Optical Gaging Products, Inc.). Two crossing lines in a small area were scanned every $50 \mu \mathrm{m}$. Because of the existing uncertainties, 20 blanks were measured and the average was used as the bevel profile.

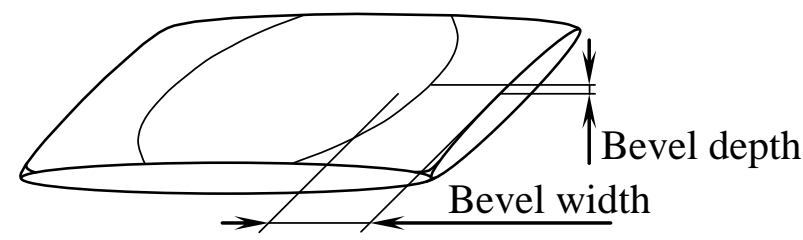

Figure 4: Bevel width and bevel depth

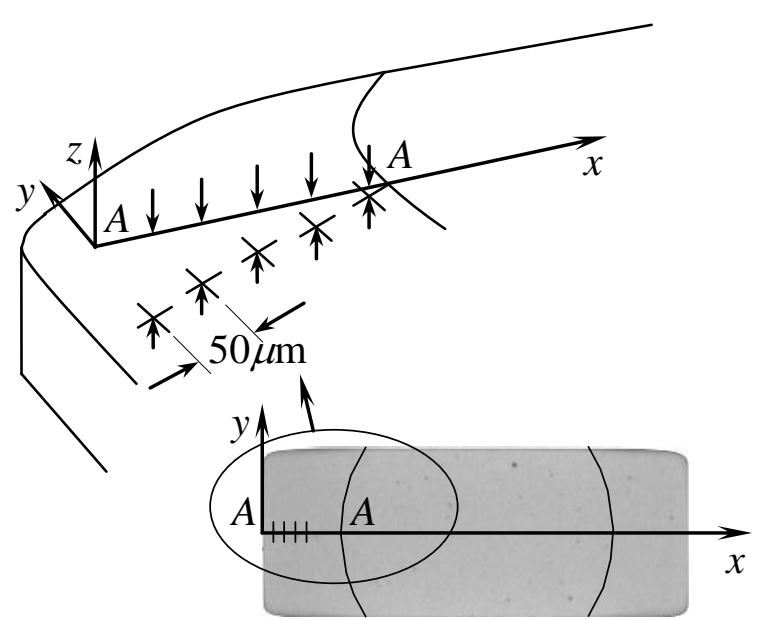

Figure 5: Bevel profile measurement

\section{Bevel profile curve fitting}

As shown in Figure 6, for the convenience of data analysis, a low order polynomial is fit to the data from laser scanning. Each data point is the average from 20 blanks. Both quadratic and cubic polynomials were tried to fit the data. Cubic polynomials were chosen based on the relative differences and $R^{2}$ (in this case $R^{2}=99.93 \%$ ). A cubic polynomial is given by 


$$
z=a_{0}+a_{1} x+a_{2} x^{2}+a_{3} x^{3}
$$

where $a_{0}, a_{1}, a_{2}$ and $a_{3}$ are regression coefficients. In order to derive these coefficients, several boundary conditions need to be satisfied. Since the blank center is flat, at some cutoff point $x=x_{0}$

$$
\begin{aligned}
& z\left(x_{0}\right)=a_{0}+a_{1} x_{0}+a_{2} x_{0}^{2}+a_{3} x_{0}^{3}=0 \\
& \left.\frac{d z}{d x}\right|_{x=x_{0}}=a_{1}+2 a_{2} x_{0}+3 a_{3} x_{0}^{2}=0
\end{aligned}
$$

By solving Eqns. (3) and (4), we have

$$
\begin{aligned}
& a_{0}=a_{2} x_{0}^{2}+2 a_{3} x_{0}^{3} \\
& a_{1}=-2 a_{2} x_{0}-3 a_{3} x_{0}^{2}
\end{aligned}
$$

Substituting Eqns. (5) and (6), Eqn. (2) is rewritten as

$$
z=a_{2}\left(x_{0}^{2}-2 x_{0} x+x^{2}\right)+a_{3}\left(2 x_{0}^{3}-3 x_{0}^{2} x+x^{3}\right)
$$

where $a_{2}$ and $a_{3}$ can be determined by least squares estimation, and $a_{0}$ and $a_{1}$ can then be calculated from Eqns. (5) and (6).

\section{Material removal rate}

In Figure 6, the abscissa is the distance from the scanning location to the blank edge in the length direction. The ordinate is the depth from the scanning location to the facet. It can be seen that the maximum material removal rate occurs at the blank edge. Because the blank edge is rounded off, the bevel depth is assumed to be approximately located at $50 \mu \mathrm{m}$ from the blank edge. Thus, the maximum material removal rate is given by

$$
m r r_{\max }=h_{b} / t
$$


As an example, the beveling profile development of experiment standard order 3 is shown in Figure 7, from which it can be seen that $h_{b}=20.3 \mu \mathrm{m}$. Because the beveling time is $54 \mathrm{~h}$, it is calculated that $m r r_{\max }=0.376 \mu \mathrm{m} / \mathrm{h}$.

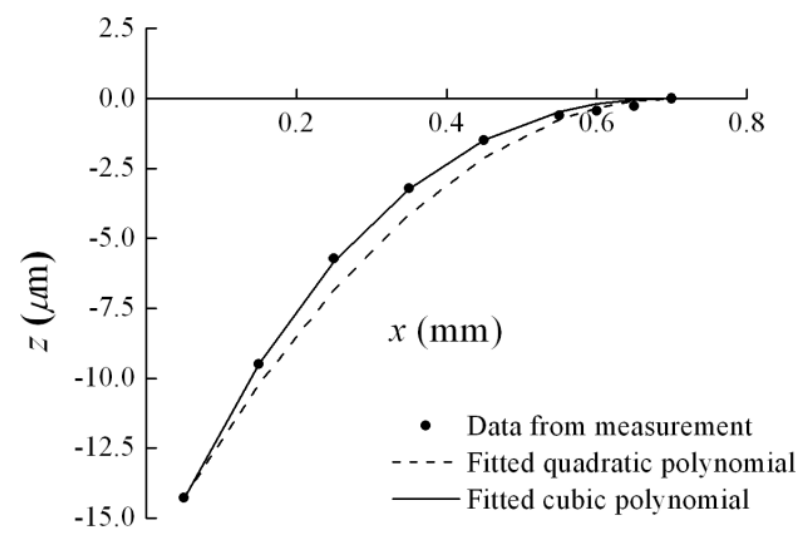

Figure 6: Data from measurement and corresponding fitted polynomials

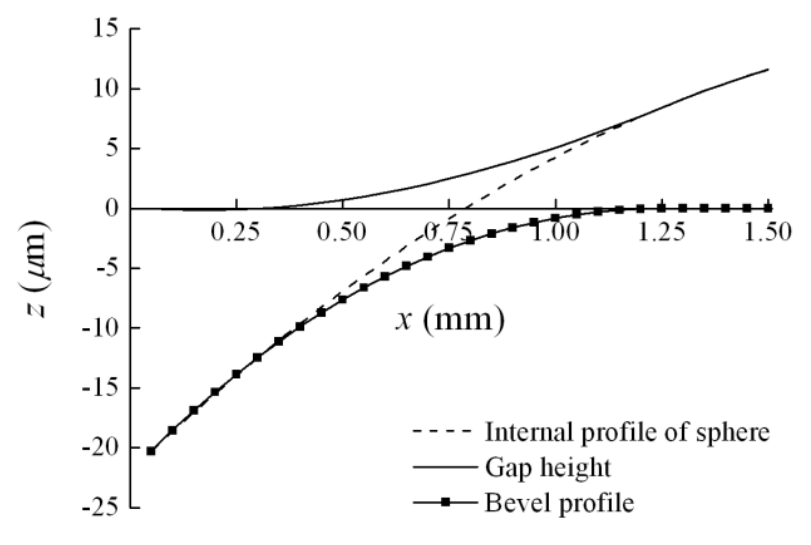

Figure 7: Bevel profile development of standard order 3

\section{Critical gap height}

As shown in Figure 8, it is assumed that at the beginning of a beveling process, the beveling barrel is in contact with the blank edge. The initial gap height at a distance of the bevel width from the blank edge, $h_{0}$ is given by 


$$
h_{0}=1000\left[\sqrt{(D / 2)^{2}-\left(L / 2-w_{b}\right)^{2}}-\sqrt{(D / 2)^{2}-(L / 2-0.05)^{2}}\right]
$$

As the beveling process progresses, the barrel-blank gap height decreases. When the designed bevel width is achieved, the gap height is the critical gap height, $h_{\text {crit }}$. With reference to Figure $8, h_{\text {crit }}$ can be found by comparing the bevel profile against the beveling barrel surface, i.e.

$$
h_{c r i t}=h_{0}-h_{b}
$$

For the example as shown in Figure 7, the critical gap height is determined to be $8.4 \mu \mathrm{m}$.

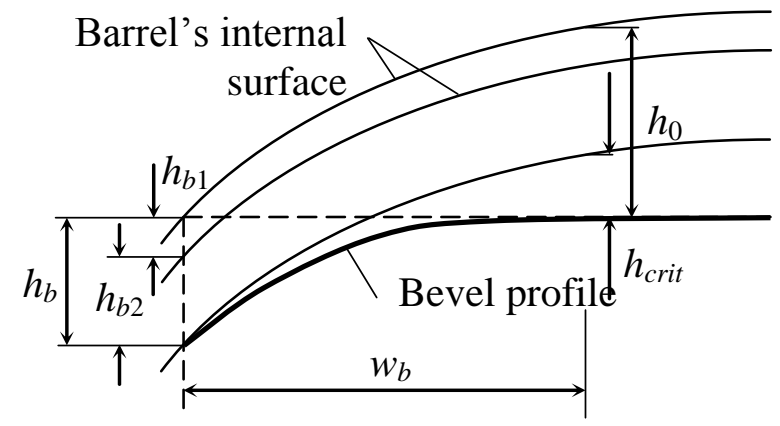

Figure 8: Determination of critical gap height

\section{Results and Discussion}

The complete data collected from experiments are shown in Table 5. The data were analyzed using a statistical software package Design-Expert®. For the maximum material removal rate, the maximum/minimum response ratio is 13.3824 . Thus, the square root transformation was chosen. In order to analyze a factorial design, the significant factor effects must be identified and separated from the insignificant effects. The Analysis of Variance (ANOVA) table is shown in Table 6. It is seen that the SST (sum of squares total) can be broken into 
two parts: model and residual. The term model means the sum of squares being explained, and it consists of significant factors. All the insignificant factors are included in the residual. The term model means the sum of squares being explained, and it consists of significant factors. All the insignificant factors are included in the residual. The model consists of two factors, i.e. machine rpm and barrel diameter, and they account for $74.49 \%$ and $18.99 \%$ of the SST, respectively. Thus, machine rpm is the most significant factor affecting the maximum material removal rate, followed by barrel diameter.

Table 5: Complete experimental data

\begin{tabular}{cccc}
\hline $\begin{array}{c}\text { Std } \\
\text { order }\end{array}$ & $\begin{array}{c}\boldsymbol{m} \boldsymbol{r} \boldsymbol{r}_{\max } \\
(\boldsymbol{\mu} \mathbf{m} / \mathbf{h})\end{array}$ & $\begin{array}{c}\boldsymbol{h}_{\text {crit }} \\
(\boldsymbol{\mu} \mathbf{m})\end{array}$ & $\begin{array}{c}\text { Frequency shift } \\
(\mathbf{k H z} / \mathbf{h})\end{array}$ \\
\hline 1 & 0.038 & 12.5 & 1.425 \\
2 & 0.152 & 11.0 & 3.547 \\
3 & 0.376 & 8.4 & 15.098 \\
4 & 0.096 & 8.8 & 2.990 \\
5 & 0.119 & 3.2 & 1.911 \\
6 & 0.455 & 4.1 & 7.061 \\
7 & 0.258 & 4.6 & 3.087 \\
8 & 0.034 & 8.8 & 0.603 \\
9 & 0.432 & 3.5 & 5.840 \\
10 & 0.138 & 2.1 & 2.738 \\
11 & 0.054 & 8.0 & 0.918 \\
12 & 0.249 & 3.5 & 3.444 \\
13 & 0.092 & 10.9 & 4.948 \\
14 & 0.041 & 16.4 & 1.295 \\
15 & 0.125 & 9.1 & 4.167 \\
16 & 0.286 & 9.2 & 7.240 \\
\hline
\end{tabular}

The regression model is given by

$$
m r r_{\max }=\left(-0.235+4.257 \times 10^{-3} \omega+1.996 \times 10^{-3} D\right)^{2}
$$

Table 6: Analysis of Variance for maximum material removal rate

\begin{tabular}{lccccll}
\hline Source & $\begin{array}{l}\text { Sum of } \\
\text { Squares }\end{array}$ & DF & $\begin{array}{l}\text { Mean } \\
\text { Square }\end{array}$ & $\begin{array}{l}\text { F } \\
\text { Value }\end{array}$ & $\begin{array}{l}\text { Prob }> \\
\text { F }\end{array}$ & \\
\hline Model & 0.384 & 2 & 0.192 & 93.140 & $<0.0001$ & significant \\
Machine rpm & 0.306 & 1 & 0.306 & 148.442 & $<0.0001$ & \\
Barrel diameter & 0.0781 & 1 & 0.0781 & 37.837 & $<0.0001$ & \\
Residual & 0.0268 & 13 & 0.00206 & & & \\
\hline
\end{tabular}




\begin{tabular}{lll}
\hline Total & 0.411 & 15 \\
\hline
\end{tabular}

The adjusted $R^{2}$ is $92.47 \%$, suggesting a good fit is obtained. The comparison of the model predictions and experimental results is given in Figure 9. The contour of the maximum material removal rate vs. machine rpm and barrel diameter is shown in Figure 10. When the barrel size is fixed, $m r r_{\max }$ at $140 \mathrm{rpm}$ is four times as much as that at $75 \mathrm{rpm}$. At the same rpm, $m r r_{\max }$ of $\phi 130$ barrels is twice as much as that that of $\phi 60$ barrels.

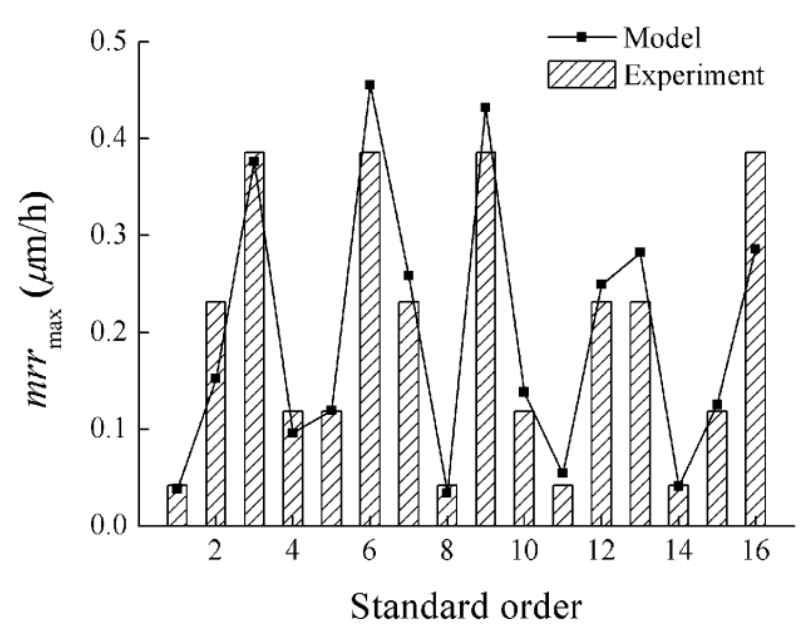

Figure 9: Comparison of model predictions and experimental results for maximum material removal rate

No transformation was applied to critical gap height. The ANOVA table is shown in Table 7. It is seen that powder type, machine rpm, barrel diameter and the interaction of machine rpm and barrel diameter account for $62 \%, 19.72 \%, 5.07 \%$ and $8.40 \%$ of the SST, and the most significant factor is powder type, followed by machine rpm, the interaction of machine rpm and barrel diameter, and barrel diameter. The regression model is given by 


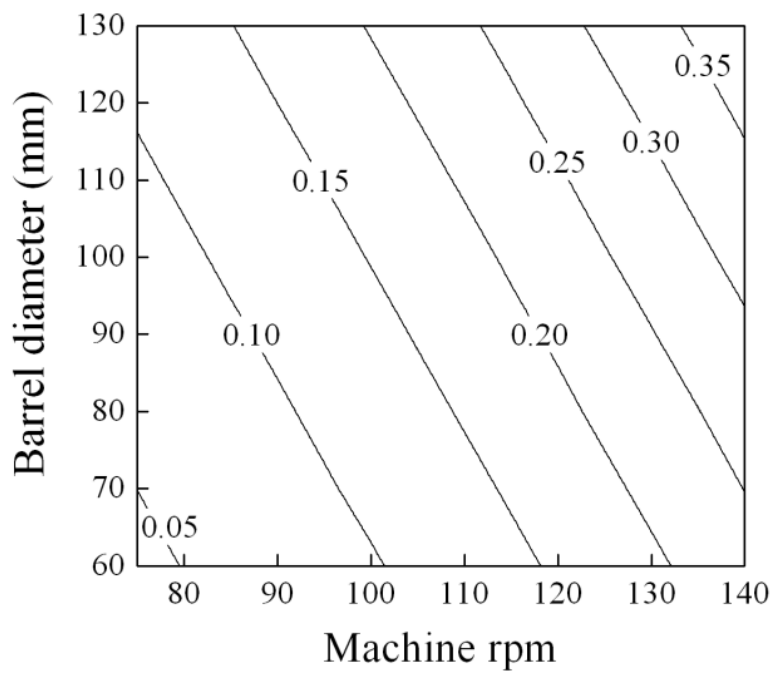

Figure 10: Contour of maximum material removal rate vs. machine rpm and barrel diameter

Table 7: Analysis of Variance for critical gap height

\begin{tabular}{lcccccc}
\hline Source & $\begin{array}{l}\text { Sum of } \\
\text { Squares }\end{array}$ & DF & $\begin{array}{l}\text { Mean } \\
\text { Square }\end{array}$ & $\begin{array}{l}\text { F } \\
\text { Value }\end{array}$ & $\begin{array}{l}\text { Prob }> \\
\text { F }\end{array}$ & \\
\hline Model & 223.488 & 4 & 55.872 & 54.424 & $<0.0001$ & significant \\
Powder type & 145.564 & 1 & 145.564 & 141.792 & $<0.0001$ & \\
Machine rpm & 11.903 & 1 & 11.903 & 11.594 & 0.0059 & \\
Barrel diameter & 46.308 & 1 & 46.308 & 45.108 & $<0.0001$ & \\
Machine rpm $\times$ Barrel diameter & 19.714 & 1 & 19.714 & 19.203 & 0.0011 & \\
Residual & 11.293 & 11 & 1.027 & & & \\
Total & 234.781 & 15 & & & & \\
\hline
\end{tabular}

$$
\begin{array}{ll}
h_{\text {crit }}=28.204-0.1192 \omega-0.1535 D+9.758 \times 10^{-4} \omega D & \text { for GC800 } \\
h_{\text {crit }}=22.171-0.1192 \omega-0.1535 D+9.758 \times 10^{-4} \omega D & \text { for GC1500 }
\end{array}
$$

The adjusted $R^{2}$ is $93.44 \%$, suggesting a good fit is obtained. The comparison of the model predictions and experimental results is given in Figure 11. The results confirm that bevel profiles are determined by the interaction of barrel-blank gap and particle size. The contour of critical gap height vs. machine rpm and barrel diameter is shown in Figure 12. When the barrel size is fixed, using finer powders produces lower critical gap height. It can be derived from Eqn. (8) that at the same initial gap height, bevel depth decreases with critical gap height. Thus, using finer powders produces larger bevel depth, i.e. steeper bevel. 


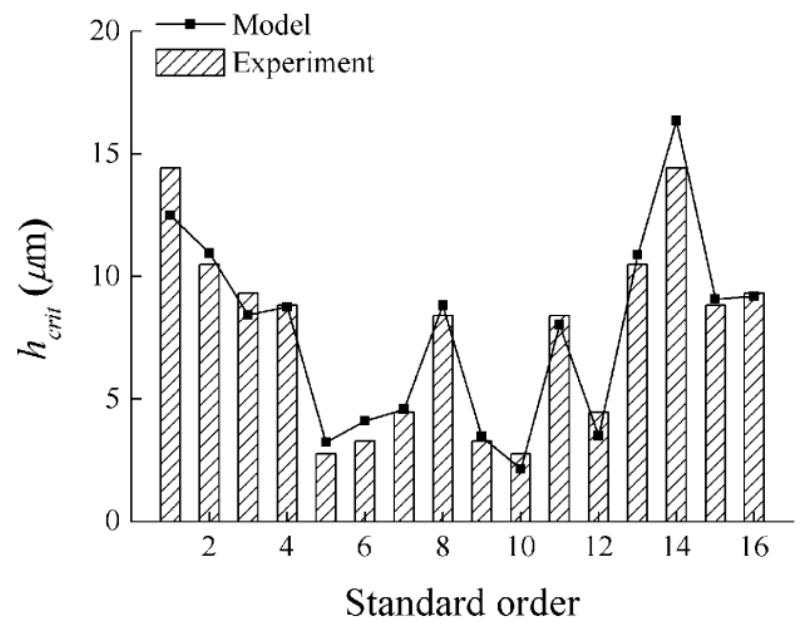

Figure 11: Comparison of model predictions and experimental results for critical gap height
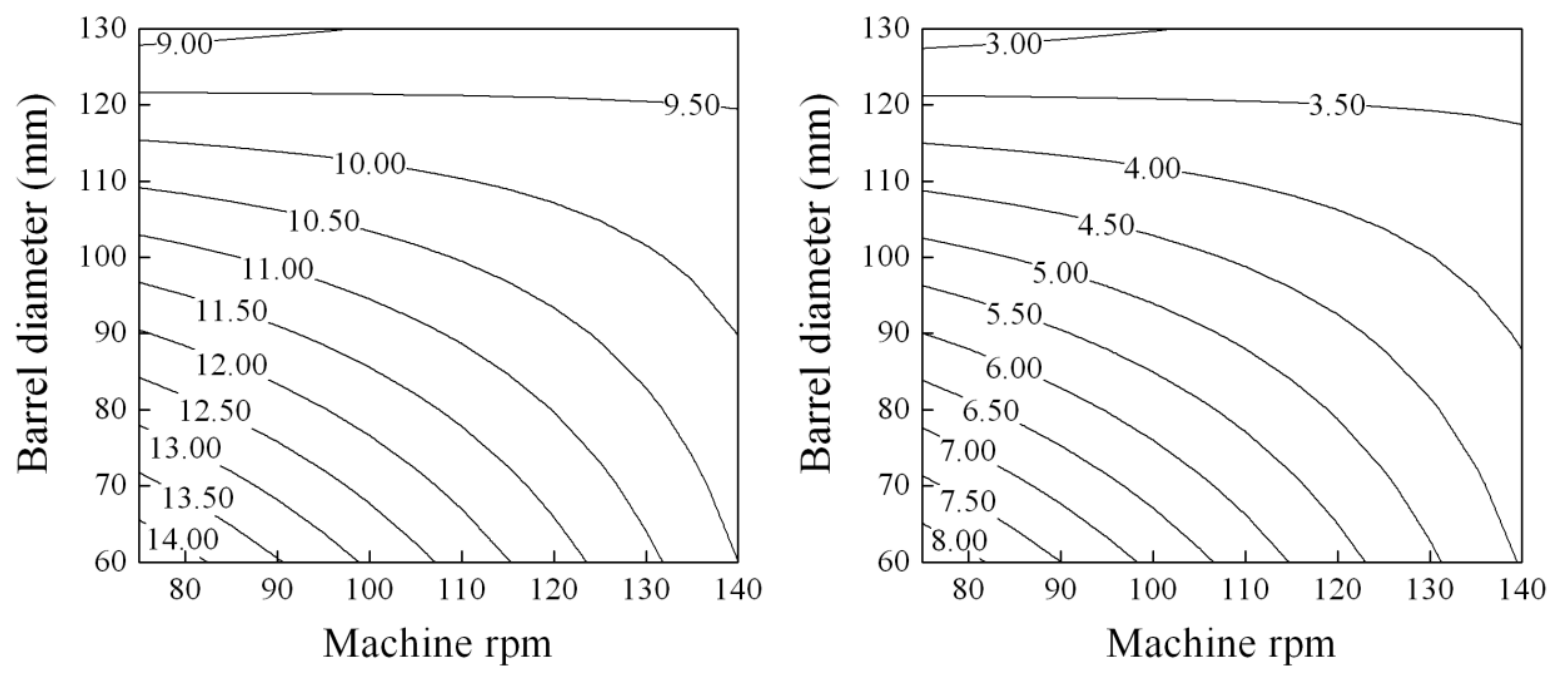

Figure 12: Contour of critical gap height vs. machine rpm and barrel diameter (Left: GC800 powders; right: GC1500 powders)

It is also seen that using a barrel of smaller diameter produces larger $h_{c r i t}$. However, decreasing the barrel diameter also significantly increases $h_{0}$. Because of this combined effect, a barrel of smaller diameter produces larger bevel depth, i.e. steeper bevel. 
In addition, when a barrel of smaller diameter is used, critical gap height increases with machine rpm; however, machine rpm has little effect when a barrel of larger diameter is used.

The logarithm transformation was chosen for frequency shift. The ANOVA is shown in Table 8. It is seen that machine rpm, barrel diameter and powder type account for $52.53 \%$, $32.34 \%$ and $7.55 \%$ of the SST, and the most significant factor is barrel diameter, followed by machine rpm and powder type. The regression model is given by

$$
\begin{array}{ll}
\Delta f=\exp \left(-1.861+1.816 \times 10^{-2} \omega+1.311 \times 10^{-2} D\right) & \text { for GC800 } \\
\Delta f=\exp \left(-2.305+1.816 \times 10^{-2} \omega+1.311 \times 10^{-2} D\right) & \text { for GC1500 }
\end{array}
$$

Table 8: Analysis of Variance for frequency shift

\begin{tabular}{lcccccc}
\hline Source & $\begin{array}{l}\text { Sum of } \\
\text { Squares }\end{array}$ & DF & $\begin{array}{l}\text { Mean } \\
\text { Square }\end{array}$ & $\begin{array}{l}\text { F } \\
\text { Value }\end{array}$ & $\begin{array}{l}\text { Prob }> \\
\text { F }\end{array}$ & \\
\hline Model & 9.731 & 3 & 3.244 & 56.775 & $<0.0001$ & significant \\
$\quad$ Powder type & 0.7867 & 1 & 0.7867 & 13.769 & 0.0030 & \\
Machine rpm & 5.576 & 1 & 5.576 & 97.591 & $<0.0001$ & \\
$\quad$ Barrel diameter & 3.369 & 1 & 3.369 & 58.965 & $<0.0001$ & \\
Residual & 0.6856 & 12 & 0.05713 & & & \\
Total & 10.417 & 15 & & & & \\
\hline
\end{tabular}

The adjusted $R^{2}$ is $91.77 \%$, suggesting a good fit is obtained. The comparison of the model predictions and experimental results is given in Figure 13. The contour of the frequency shift vs. the machine rpm and barrel diameter is shown in Figure 14. It is seen that frequency shift increases with machine rpm, since material removal increases with machine rpm. It is also seen that frequency shift increases with barrel diameter, which can be explained by that when the barrel diameter increases, the gap height decreases and more abrasion in the facet occurs. Likewise, using finer powders can reduce the frequency shift. 


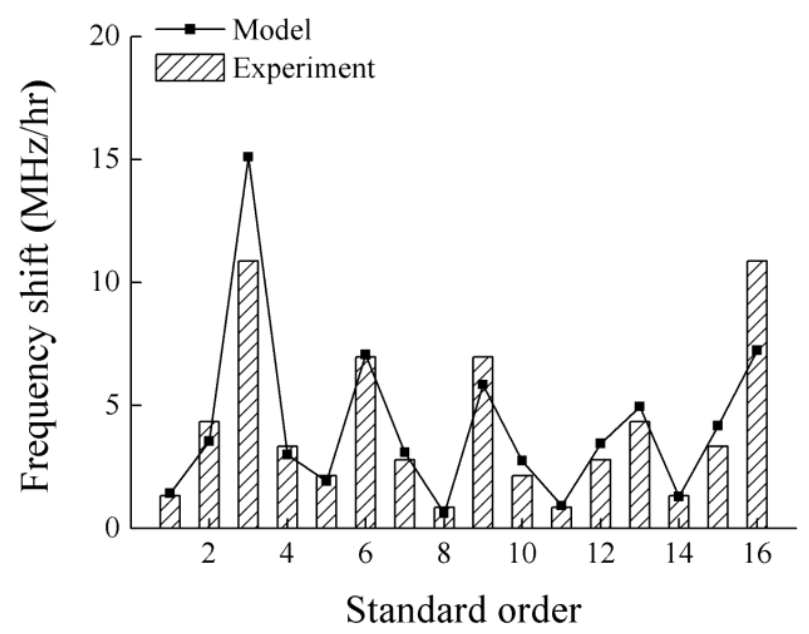

Figure 13: Comparison of model predictions and experimental results for frequency shift
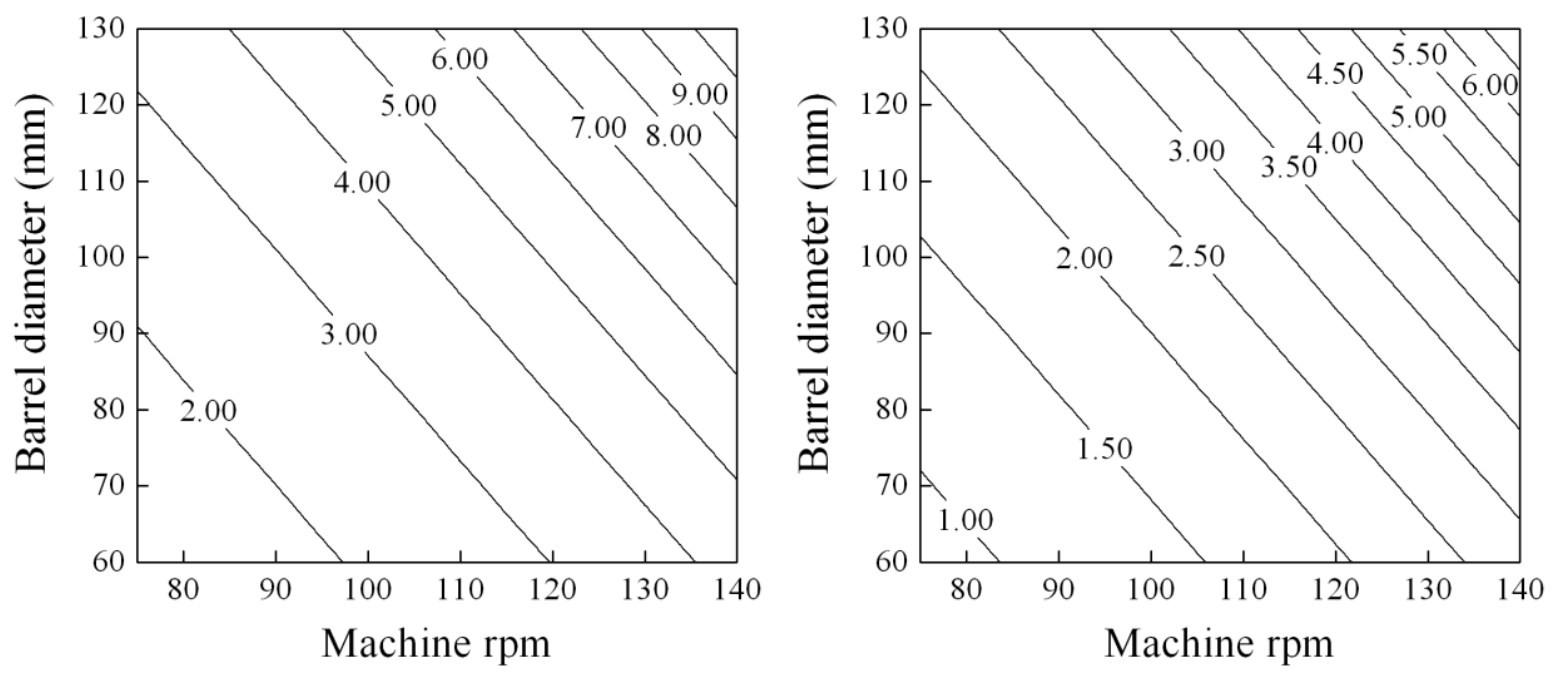

Figure 14: Contour of frequency shift vs. machine rpm and barrel diameter (Left: GC800 powders; right: GC1500 powders)

\section{Conclusions}

An experimental study on the beveling of quartz crystal blanks is presented in this paper.

Seven possibly relevant process factors: blank quantity, powder/blank ratio, powder type, machine rpm, powder changing time, barrel diameter and powder heating were identified.

The influences of these process factors on material removal rate, bevel profile and frequency 
shift were studied using DOE. The major findings from this experimental study are summarized as follows:

1. Machine rpm has the most significant effect on material removal rate, followed by barrel diameter. Material removal rate increases with machine rpm and barrel diameter;

2. Steeper bevel can be achieved by using barrels of smaller diameter and finer powders; and

3. Machine rpm has the most significant effect on frequency shift, followed by the barrel diameter and powder type. Frequency shift increases with machine rpm and barrel diameter. Using finer powders can reduce frequency shift.

The results from this study are very useful for the process design of new crystal resonators. Process factors including machine rpm, barrel diameter and powder type can be adjusted to achieve the desired bevel profile efficiently. Since the purpose of this study was screening design, only two levels for each variable were chosen. Because of the non-linear functional relationships, more data are required for developing a full process model. This will be addressed in our future work.

\section{Nomenclature}
D: $\quad$ barrel diameter $(\mathrm{mm})$
$d_{p}: \quad$ average diameter of beveling powders $(\mu \mathrm{m})$
$f: \quad$ blank frequency $(\mathrm{MHz})$
$H: \quad$ blank thickness $(\mathrm{mm})$
$h$ : $\quad$ blank-barrel gap height $(\mu \mathrm{m})$ 


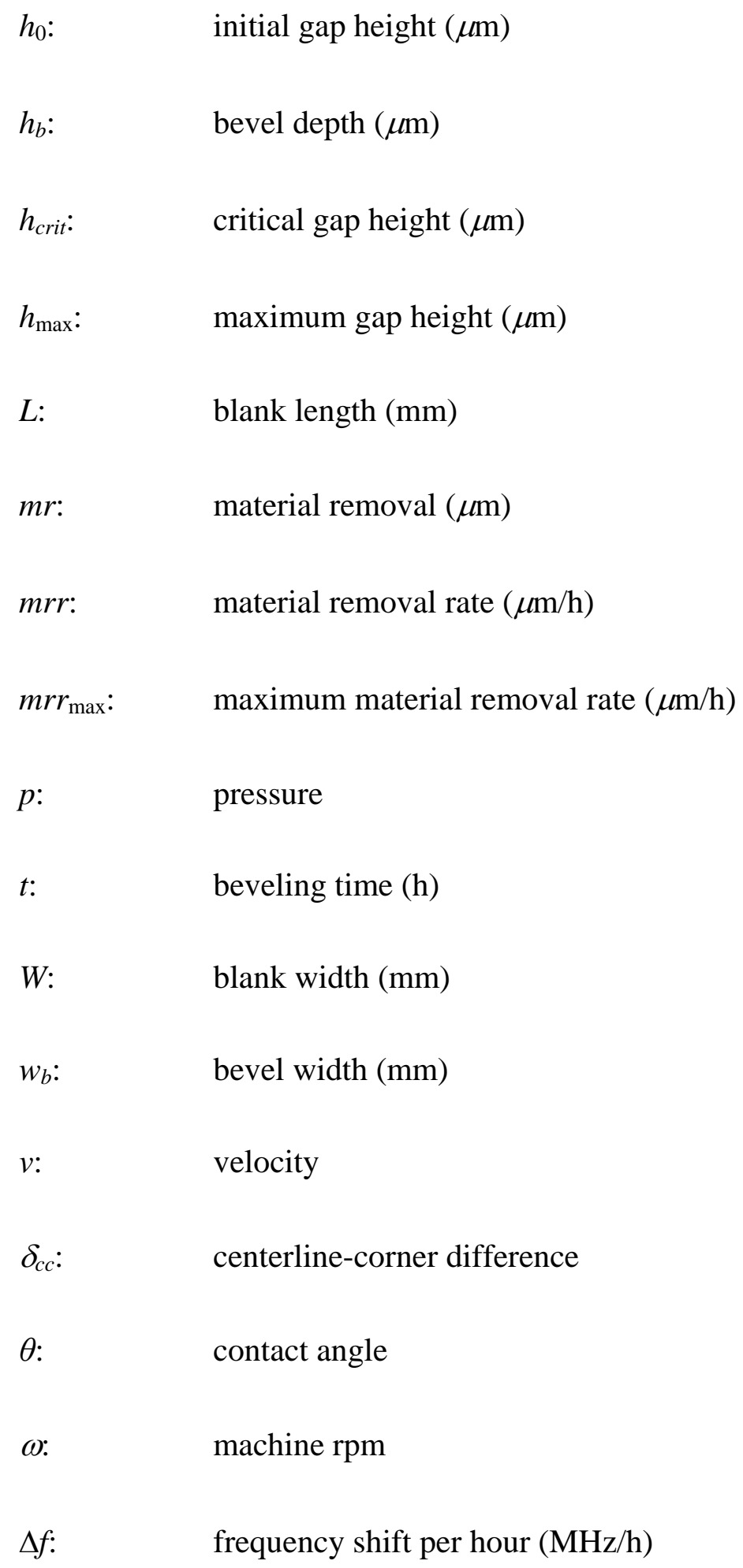

\section{References}

Chen, P.-Y., Tsai, M.-H., Yeh, W.-K., Jing, M.-H. and Chang, Y. (2010a), Relationship between wafer edge design and its ultimate mechanical strength. Microelectronic Engineering, 87(11), 2065-2070. 
Chen, P.-Y., Tsai, M.-H., Yeh, W.-K., Jing, M.-H. and Chang, Y. (2010b), Relationship between wafer fracture reduction and controlling during the edge manufacturing process. Microelectronic Engineering, 87(10), 1809-1815.

Evans, C. J., Paul, E., Dornfeld, D., Lucca, D. A., Byrne, G., Tricard, M., Klocke, F., Dambon, O. and Mullany, B. A. (2003), Material removal mechanisms in lapping and polishing. Annals of the CIRP, 52(2), 611-633.

Koyama, M., Watanabe, Y., Sekimoto, H. and Oomura, Y. (1996), An experimental study of frequency jumps during the aging of quartz oscillators. IEEE Transactions on Ultrasonic, Ferroelectrics, and Frequency Control, 43(5), 907-910.

Preston, F. W. (1927), The theory and design of plate glass polishing machine. Journal of the Society of Glass Technology, 11(44), 214-256.

Salt, D. (1987), Hy-Q Handbook of Quartz Crystal Devices. Berkshire, England, Van Nostrand Reinhold (UK) Co. Ltd.

Sekimoto, H., Goka, S., Ishizaki, A. and Watanabe, Y. (1997), Frequency-temperature behavior of spurious vibrations of rectangular AT-cut quartz plates. IEEE International Frequency Control Symposium, 710-714.

Virgil, E. B. (1982), Introduction to Quartz Crystal Unit Design. New York, Van Nostrand Reinhold Ltd.

Williams, J. A. and Hyncica, A. M. (1992), Mechanisms of abrasive wear in lubricated contacts. Wear, 152, 57-74. 